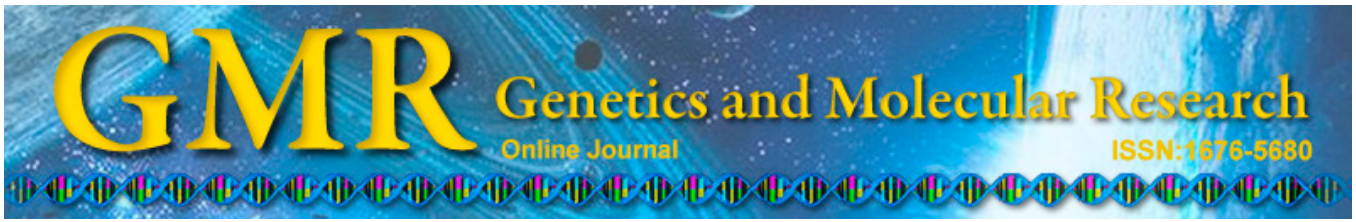

\title{
Transcriptome analysis of skeletal muscle at prenatal stages in Polled Dorset versus Small-tailed Han sheep
}

\author{
N. Liu ${ }^{1 *}$, J.N. He ${ }^{1 *}$, W.M. Yu ${ }^{1}$, K.D. Liu' ${ }^{2}$ M. Cheng ${ }^{2}$, J.F. Liu ${ }^{1}$, Y.H. He ${ }^{1}$, \\ J.S. Zhao ${ }^{2}$ and X.X. Qu ${ }^{3}$ \\ ${ }^{1}$ College of Animal Science and Technology, Qingdao Agricultural University, \\ Qingdao, China \\ ${ }^{2}$ Qingdao Institute of Animal Science and Veterinary Medicine, Qingdao, China \\ ${ }^{3}$ Shandong Chief Animal Husbandry Station, Jinan, China \\ *These authors contributed equally to this study. \\ Corresponding authors: J.S. Zhao / X.X. Qu \\ E-mail: zhaojinshande@sohu.com / qu1964@163.com
}

Genet. Mol. Res. 14 (1): 1085-1095 (2015)

Received May 15, 2014

Accepted September 23, 2014

Published February 6, 2015

DOI http://dx.doi.org/10.4238/2015.February.6.12

\begin{abstract}
The objectives of the present study were to identify additional genes that may play important roles in the regulation of skeletal muscle growth and development, and to provide fundamental information for understanding the underlying molecular mechanisms. Eighteen cDNA libraries were constructed from the longissimus muscle of Polled Dorset (PD) and Small-tailed Han (SH) fetuses. To reveal the differences between the two species, we analyzed the differences in gene expression in 60-, 90- and 120-day fetal skeletal muscle by applying Agilent ovine genome-wide microarray. In this study, we obtained 17,704 genes using a chip containing 39,242 probes. There were 88 differentially expressed genes in the 60-day group $(\mathrm{P}<0.05), 128$ genes in the 90-day group $(\mathrm{P}<0.05)$, and 340 genes in the 120-day group $(\mathrm{P}<0.05)$ between the two breeds. The differentially expressed genes were grouped in different $\mathrm{GO}$ categories and signaling pathways. These
\end{abstract}


results suggested that there are many genetic differences in the muscle growth and development transcriptomes between these two breeds. This study laid the foundation for future genomic research in sheep.

Key words: Skeletal muscle; Transcriptome; Gene expression; Sheep

\section{INTRODUCTION}

Prenatal skeletal muscle development is an important determinant factor for muscularity and meat quality (Rehfeldt et al., 2004). In large precocial species such as sheep (Ashmore et al., 1972; Maier et al., 1992) and cattle (Russell and Oteruelo, 1981), the maximum myofiber complement of a muscle is achieved prior to birth. More than three waves of myogenic cells appear in sheep, and most myofibers form after 60 days of gestation (Wilson et al., 1992; McCoard et al., 2000). Among many factors, genetics is the most fundamental. With the development of high-throughput analytical technologies, the relationships between various genetic factors from a global and systematic aspect become easy to understand. Polled Dorset sheep (PD) is a foreign breed with a white wool-free face. Its main distinguishing features are hornless appearance, long, lean square body set on short legs, pink skin and 'spongy' shortstapled wool. The characteristics of this sheep breed such as rapid growth rate, superior fleshing and muscular development as well make it ideally suited for the meat trade. Also, PD rams are the most commonly used as sires for the production of prime lambs, while the Small-tailed Han sheep (SH) is an excellent local breed in China because of its significant characteristic of hyperprolificacy, with a mean litter size of 2.61(National Commission for Livestock and Poultry Genetic Resources , 2011). Also, with long, strong limbs and an elliptical fan-shaped tail, it has a slower growth rate and is a dual-purpose breed, where it is used as a female parent in cross breeding programs. In the present study, we performed transcriptomic analysis of longissimus muscle, collected from PD and SH sheep by using the specialized transcriptome-wide sheep oligo DNA microarray. Our objectives were to identify some putative candidate genes that are valuable for meat yield and quantity and to provide a theoretical basis for understanding the molecular mechanisms underlying muscle growth and development.

\section{MATERIAL AND METHODS}

\section{Animals and tissue preparation}

All animal procedures were performed according to protocols approved by the Committee on Animal Care and Use for Biological Studies, Shandong Province, China. PD and SH ewes (nine for each breed) were selected on the basis of similar age, body weight and body size. After these animals were subjected to pre-feeding for 45 days, they were mated with the ram of corresponding breed, and the date of mating was recorded. The fetuses were selected at 60, 90 and 120 days of gestation, and the longissimus muscle tissue was rapidly and manually dissected from each fetus. These samples were snap-frozen in liquid nitrogen and stored at $-80^{\circ} \mathrm{C}$ until further use. At least three fetuses from each stage were used for constructing the library. Subsequently, skeletal muscles from 18 fetuses were used for QPCR validation. Total RNA was extracted from the frozen longissimus muscle using TRIzol reagent (Invitrogen Inc., Carlsbad, CA, USA) according to manufacturer instructions. RNA integrity was evaluated by 
gel electrophoresis and RNA purity was checked by the $28 \mathrm{~S} / 18 \mathrm{~S}$ ratio and RIN value. RNA samples with RIN value greater than seven and $28 \mathrm{~S} / 18 \mathrm{~S}$ ratio greater than 0.7 were selected for microarray analysis.

\section{Microarray experiment}

The new specialized and standardized transcriptome-wide sheep microarray (Agilent Technologies, Santa Clara, CA, USA) contained 39,242 sheep probes sourced from RefSeq and UniGene. The oligo DNA microarray was 44,000 nucleotides in size. Total RNA was amplified and labeled by Low Input Quick Amp Labeling kit, One-Color (Agilent Technologies), following manufacturer instructions. Labeled cRNA was purified using the RNeasy mini kit (QIAGEN, GmBH, Germany). Each slide was hybridized with $1.65 \mu \mathrm{g}$ Cy3-labeled cRNA using the Gene Expression Hybridization kit (Agilent Technologies) in a Hybridization Oven (Agilent Technologies), according to manufacturer instructions. After 17-h hybridization, slides were washed in staining dishes (Thermo Shandon, Waltham, MA, USA) with Gene Expression Wash Buffer kit (Agilent Technologies), following manufacturer instructions. Slides were scanned with an Agilent Microarray Scanner (Agilent Technologies) with default settings, i.e., dye channel: green, scan resolution $=5 \mu \mathrm{m}$, PMT 100\%, 10\%, 16 bit.

\section{Statistical analysis of microarray data}

Data were extracted with Feature Extraction software 10.7 (Agilent Technologies). Raw data were normalized by the Quantile algorithm, Gene Spring Software 11.0 (Agilent Technologies). One-way ANOVA and the $t$-test were used for screening differentially expressed genes (DEGs), on the premise that no relationships existed between the data at different time points. The thresholds for significance were $\mathrm{P}<0.05$ and a 2 -fold change.

\section{Gene Ontology (GO) enrichment analysis}

The GO project is a major bioinformatics initiative with the aim of standardizing the representation of gene and gene product attributes across species and databases. The project provides a controlled vocabulary of terms for describing gene product characteristics and gene product annotation data from GO Consortium members, as well as tools to access and process these data. In this study, the analysis was performed by DAVID database, taking $\mathrm{P}<0.05$ as the threshold. This kind of analysis is able to recognize the main biological functions that DEGs exercise.

\section{Quantitative real-time PCR (qRT-PCR) for microarray data}

cDNA was synthesized from $1 \mu \mathrm{g}$ total RNA using the PrimeScript RT reagent kit (Takara Technologies, Code: DRR037A) in a $20-\mu \mathrm{L}$ reaction mixture. qRT-PCR was performed and the amount of amplified DNA was monitored by fluorescence at the end of each cycle using CFX 96 (Bio-Rad Laboratories). Thermal cycling consisted of an initial step at $95^{\circ} \mathrm{C}$ for $110 \mathrm{~s}$ followed by 40 cycles at $95^{\circ} \mathrm{C}$ for $10 \mathrm{~s}$ and $61^{\circ} \mathrm{C}$ for $33 \mathrm{~s}$. $R P L P 0$ was chosen as the reference gene for normalization of all data because it was expressed more stably (Laborda, 1991; Fleming-Waddell et al., 2007; Vuocolo et al., 2007; White et al., 2008). Each qRT-PCR 
(in $20 \mu \mathrm{L}$ ) contained $10 \mu \mathrm{L} 2 \mathrm{X}$ real-time mix, $0.8 \mu \mathrm{L}$ of each primer, $2 \mu \mathrm{L}$ normalized template cDNA, and $6.4 \mu \mathrm{L}$ water. Each plate was repeated three times in independent runs for all reference and selected genes. Gene expression was evaluated by the $2^{-\triangle \Delta \mathrm{CT}}$ method (Livak and Schmittgen, 2001). Gene expression ratios were normalized to the RPLP0 gene in the same sample, and the primer information are shown in Table 1.

Table1. Primer sequences and PCR product sizes of genes selected for validation by qRT-PCR.

\begin{tabular}{|c|c|c|c|c|}
\hline Gene & & Primer sequence (5'-3') & Annealing temperature $\left({ }^{\circ} \mathrm{C}\right)$ & Product size \\
\hline \multirow[t]{2}{*}{ CD19 } & $\mathrm{F}$ & CTGTGCTCCACCTAACAGCA & 60 & 252 \\
\hline & $\mathrm{R}$ & TCGGGCAGTAACAGAACCAC & 60 & \\
\hline \multirow[t]{2}{*}{$M R C L 3$} & $\mathrm{~F}$ & TGCTGACCACAATGGGAGAC & 60 & 293 \\
\hline & $\mathrm{R}$ & AGAGATGCATGTGCCCCAAA & 58 & \\
\hline \multirow[t]{2}{*}{ MSTN } & $\mathrm{F}$ & TGAGAACAGCGAGCAGAAGG & 60 & 183 \\
\hline & $\mathrm{R}$ & GGAGCCTTGGGCAAAAGTTG & 60 & \\
\hline \multirow[t]{2}{*}{ IFNARIE } & $\mathrm{F}$ & GAAAACAGCTGCACATGCCA & 58 & 637 \\
\hline & $\mathrm{R}$ & AAATGCCACCCCTCAGGATG & 60 & \\
\hline \multirow[t]{2}{*}{ HOXA5 } & $\mathrm{F}$ & AGACCCTGGAGCTGGAGAAG & 62 & 93 \\
\hline & $\mathrm{R}$ & TCTCCGAGAGGCAAAGAGCA & 60 & \\
\hline \multirow[t]{2}{*}{ CA4 } & $\mathrm{F}$ & CGTGCAAAACAACGGGCATA & 58 & 241 \\
\hline & $\mathrm{R}$ & CTCATCTTCGGCGAACTGGT & 60 & \\
\hline \multirow{2}{*}{ MYO9A } & $\mathrm{F}$ & GGCTGCTGAGGTGATTGACT & 60 & 168 \\
\hline & $\mathrm{R}$ & CGATTTTCCAGAGCCATGCG & 60 & \\
\hline \multirow[t]{2}{*}{ CLDN7 } & $\mathrm{F}$ & CCATGACGGGAGGCATCATT & 60 & 225 \\
\hline & $\mathrm{R}$ & CAGCTTTGCTCTCACTCCCA & 60 & \\
\hline \multirow[t]{2}{*}{ TPM4 } & $\mathrm{F}$ & GCCGAGGTGTCCGAACTAAA & 60 & 167 \\
\hline & $\mathrm{R}$ & CGGGTCTCAGCCTCTTTCAG & 62 & \\
\hline \multirow[t]{2}{*}{ GATAD $2 A$} & $\mathrm{~F}$ & СTCTGCTACTGCTCATCCCG & 62 & 343 \\
\hline & $\mathrm{R}$ & CCCAAACGCAAACCCTGAAG & 60 & \\
\hline \multirow[t]{2}{*}{$C A V 1$} & $\mathrm{~F}$ & AGGGCAACATCTACAAGCCC & 60 & 121 \\
\hline & $\mathrm{R}$ & TCGTTGAGATGCTTGGGGTC & 60 & \\
\hline \multirow{2}{*}{ MYOT } & $\mathrm{F}$ & ACTCCATCAAAGCCAGGAGC & 60 & 128 \\
\hline & $\mathrm{R}$ & GGGGTGGGGTCTTGAATCTG & 62 & \\
\hline \multirow{2}{*}{ GAPDH } & $\mathrm{F}$ & CCGCATCCCTGAGACAAGAT & 60 & 209 \\
\hline & $\mathrm{R}$ & TTCCCGTTCTCTGCCTTGAC & 60 & \\
\hline \multirow[t]{2}{*}{ RPLPO } & $\mathrm{F}$ & TCTCCTTCGGGCTGGTCATC & 62 & 131 \\
\hline & $\mathrm{R}$ & GCACACGCTGGCAACATTG & 60 & \\
\hline
\end{tabular}

\section{RESULTS}

\section{Microarray data summary}

Eighteen cDNA libraries were constructed using longissimus muscles from PD and SH fetuses. We applied the first specialized and standardized transcriptome-wide sheep oligo DNA microarray to determine gene expression levels. The results showed that the average detectable rate of all probe sets reached $71.14 \%$ (Table 2), which enabled us to evaluate the changes in gene expression. The raw data were normalized and evaluated. We analyzed gene expression levels of fetuses at three different stages of individuals of two sheep breeds, using a cutoff of $\mid$ fold change $\mid<2$ with $\mathrm{P}<0.05$. The volcano plot is shown in Figures 1 and 2 . A pool of differentially expressed probes from the two groups was used for a systematic hierarchical clustering to gain insight into the transcriptome-wide similarities between 18 individuals (Figure 3). We found that individuals at the same developmental stage were clustered together, indicating that differences derived during development were larger than those from the genetic backgrounds between the breeds. 
Table 2. Results for quality control of oligo DNA microarray.

\begin{tabular}{lcc}
\hline Name & CV value (\%) & Detectable rate (\%) \\
\hline SH60-1 & 5.67 & 74.53 \\
SH60-2 & 4.58 & 72.68 \\
SH60-3 & 4.66 & 72.9 \\
SH90-1 & 4.12 & 71.82 \\
SH90-2 & 5.55 & 72.00 \\
SH90-3 & 4.4 & 70.88 \\
SH120-1 & 4.95 & 67.66 \\
SH120-2 & 4.93 & 68.52 \\
SH120-3 & 5.35 & 66.26 \\
PD60-1 & 4.55 & 71.3 \\
PD60-2 & 4.84 & 73.65 \\
PD60-3 & 4.38 & 69.1 \\
PD90-1 & 5.89 & 70.51 \\
PD90-2 & 4.93 & 71.15 \\
PD90-3 & 4.48 & 72.66 \\
PD120-1 & 5.04 & 68.76 \\
PD120d-2 & 5.07 & 68.84 \\
PD120-3 & 4.68 & 70.82 \\
\hline
\end{tabular}

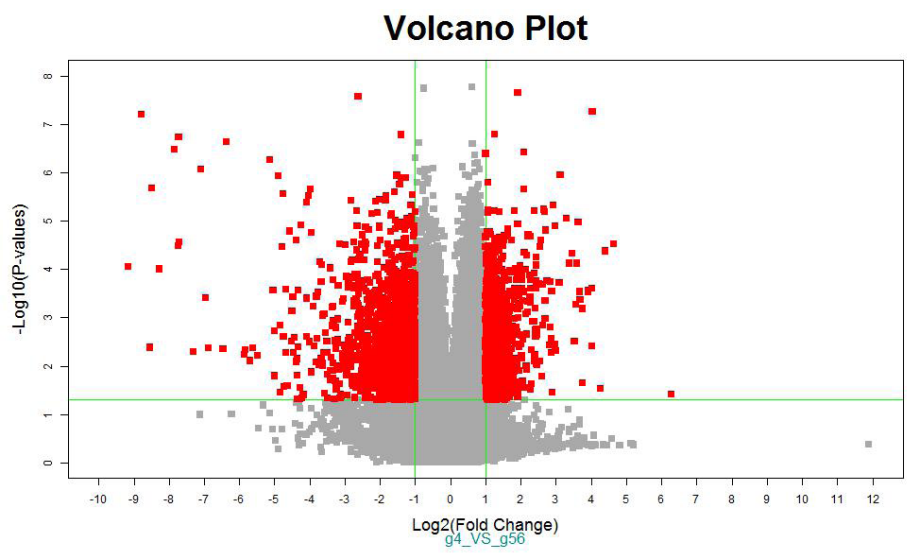

Figure 1. Volcano plot of PD at different stages.

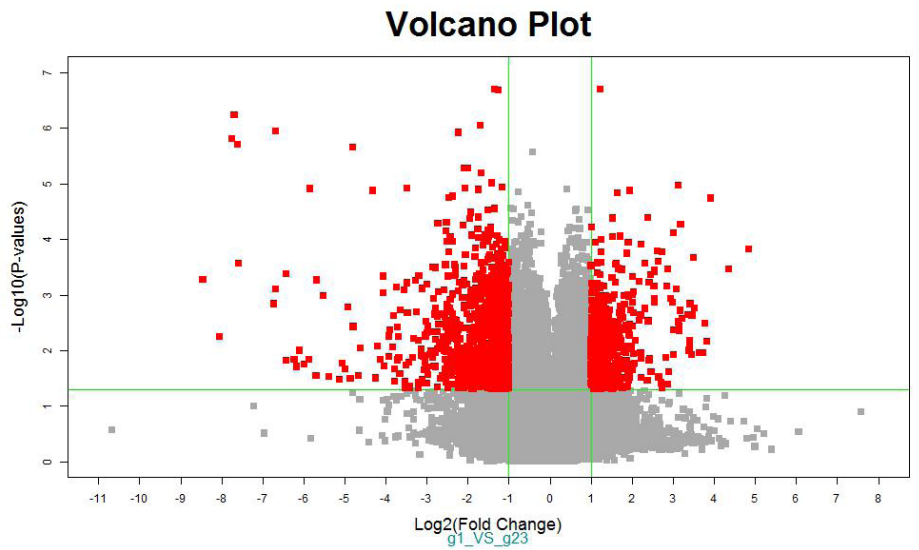

Figure 2. Volcano plot of SH at different stages. 


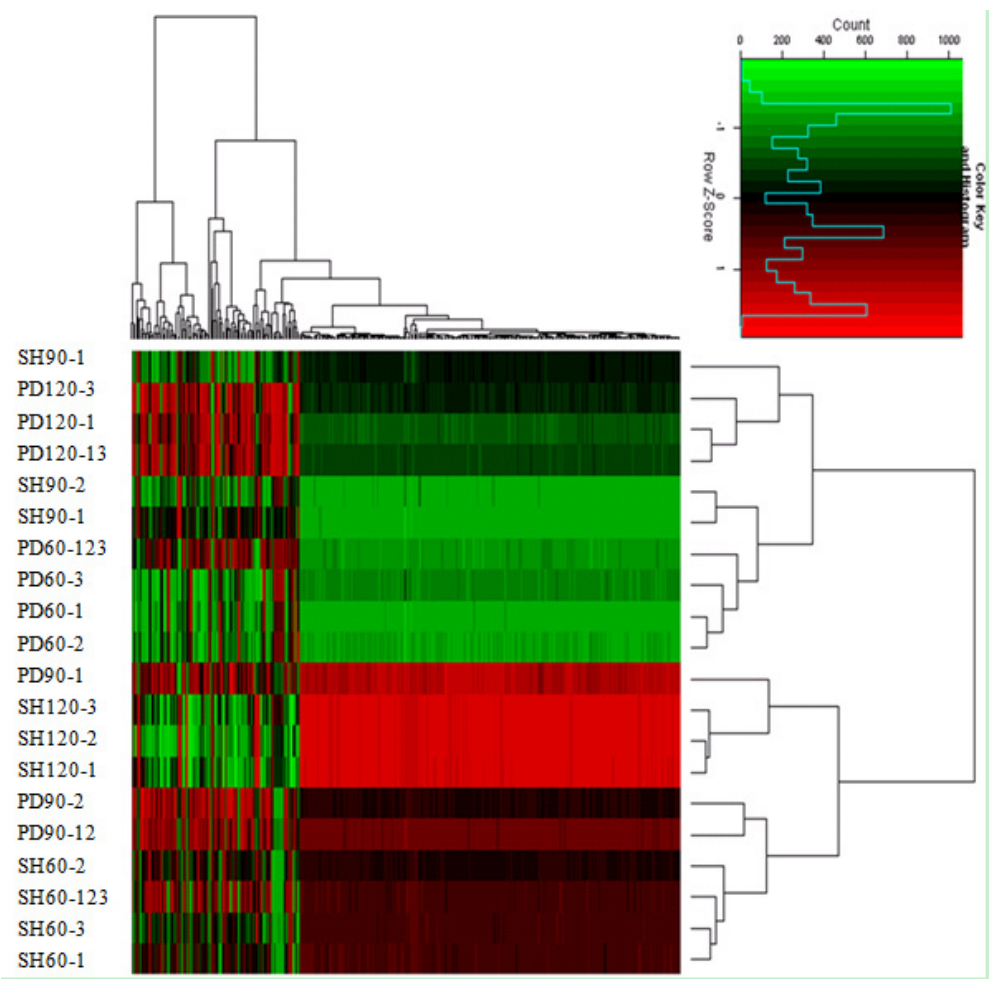

Figure 3. Hierachical clustering of differentially expressed genes.

\section{Gene expression in skeletal muscle at various developmental stages between two sheep breeds}

At 60-day stage, a total of 88 genes were differentially expressed between the two sheep breeds, including 65 known genes, in which 33 genes were upregulated and 32 downregulated in $\mathrm{PD}$. The PPP1R15A and MRPL1 genes were uniquely expressed in $\mathrm{SH}$, and the $R A R G, C A 4$ and $C 1 Q T N F 1$ genes were uniquely expressed in PD. At 90-day stage, a total of 128 genes were shown to be significantly differentially expressed between the two breeds, including 97 known genes, in which 39 genes were upregulated and 58 downregulated in PD. The ITGBL1, CPXM2, MRPL1 genes were uniquely expressed in SH, and SIGLEC14 and $A P O B E C 3 G$ were uniquely expressed in PD. At 120 days, a total of 340 genes were differentially expressed between the two breeds, including 280 known genes. Compared with PD, 231 genes were upregulated and 49 downregulated in SH. The HPSE, RAB33B, MRPL1, and PPP1R15A genes were uniquely expressed in SH, and F2, ADIPOQ, ASGR1, FABP4, $M G A T 1, H I N T 1$, and $H L A-D Q B 1$ were uniquely expressed in PD. The numbers of known DEG at various developmental stages between the two breeds were 65, 97 and 280, respectively, and the upregulated genes were 33, 39 and 231 in PD sheep, as shown in Figure 4. With fetal growth and development, the number of DEGs increased, consistent with the rules of sheep skeletal muscle development. 


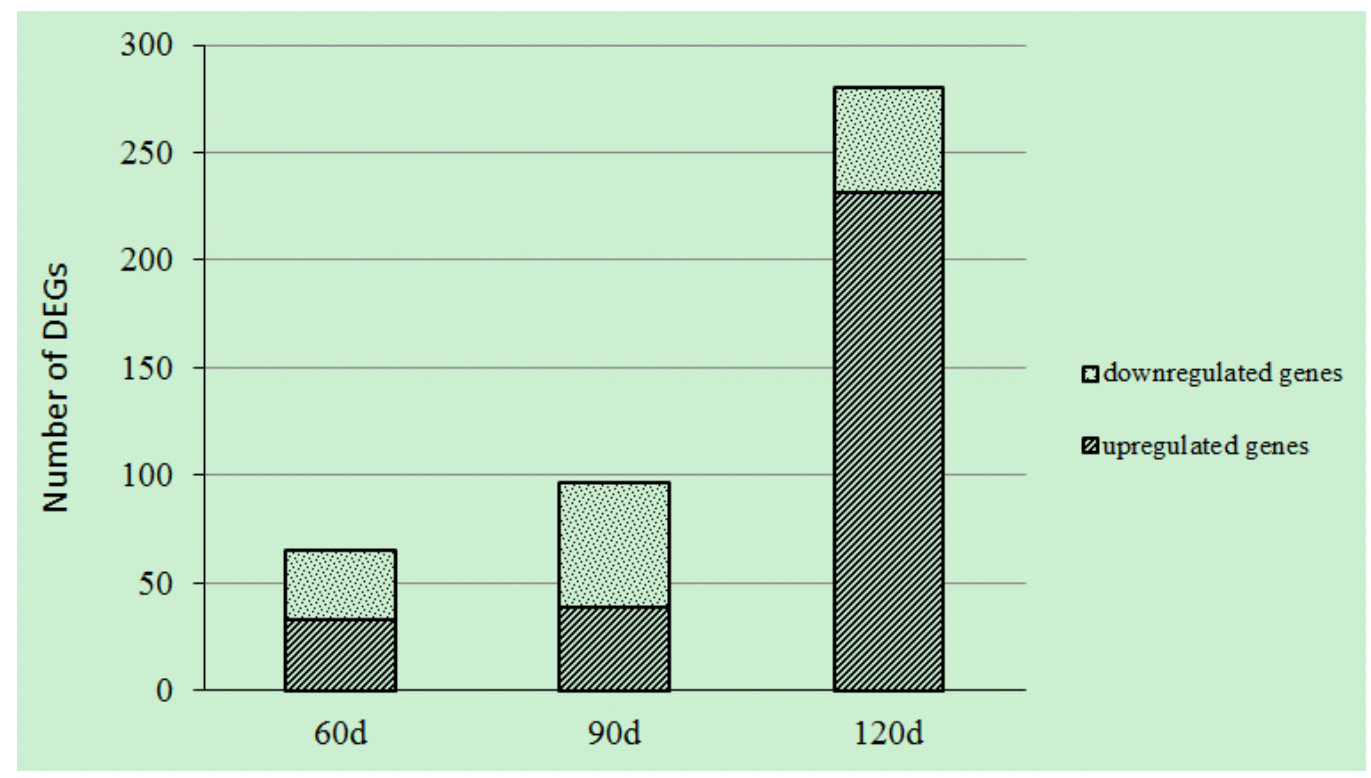

Figure 4. Number of differentially expressed genes (DEGs) between two breeds.

\section{DEG GO analysis}

To gain further insight into the biological importance of the DEGs, a GO analysis was performed by applying the DAVID database, and the results are shown in Figure 5A, B and $\mathrm{C}$. The DEGs were grouped in the cellular component, molecular function and biological process categories. In general, the categories of molecular function involved in myogenesis were similar between PD and SH sheep. However, the numbers of DEGs involved in certain biological processes were quite different between PD and SH. For instance, more genes involved in cyclase activity and toxin binding were expressed in SH. In contrast, more DEGs involved in ectopic enzyme activity, demethylation activity of bone structure, muscle structure composed of prominent vitamin transport activity, lipid-binding aspects of metalloenzymes, and kinase activity were identified in PD. In the cellular component category, there were more genes involved in the intermediates and the outer edge of the structure of cells in $\mathrm{SH}$, and more genes were grouped in the spindle fibers, perikaryon, killer cells, their positive or negative regulation of immune response, and immune system development in PD. For the biological process category, there were more genes involved in cell aging, control of virus propagation, fetal development and the developmental process of pigmentation, and organ growth in SH. Also, more genes were categorized in transposition, positive or negative regulation of virus propagation, embryo implantation, keratinization, positive and negative regulation of killer cells and apoptosis in PD.

\section{DEG pathway analysis}

A pathway analysis was performed by Biocarta and KEGG, to show the most repre- 
sented pathways among the DEGs. Of the known genes, 582 DEGs in PD versus SH, were enriched in 327 pathways including 172 Biocarta and 155 KEGG pathways. A total of 934 DEGs in PD versus SH were enriched in 390 pathways including 220 Biocarta and 170 KEGG pathways.

A

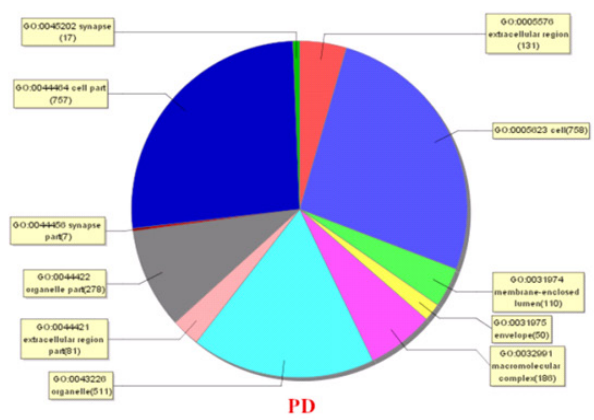

B

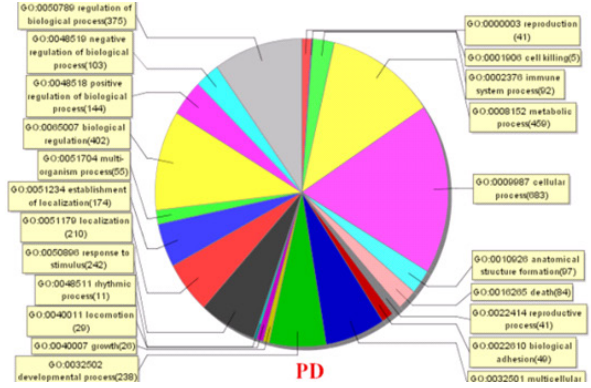

C

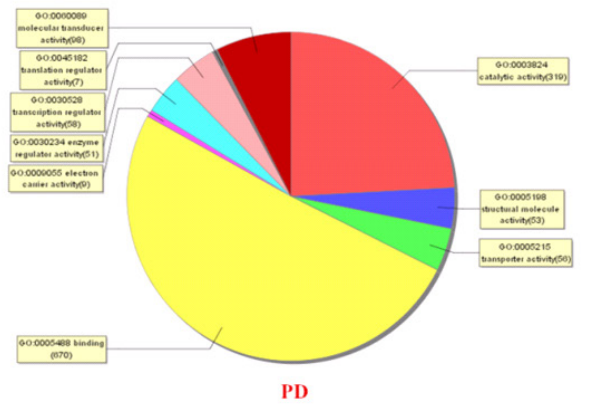

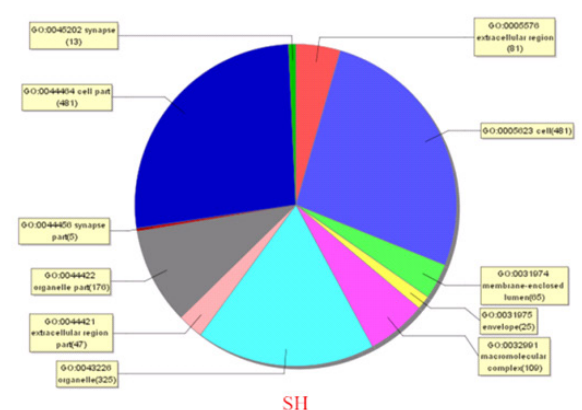
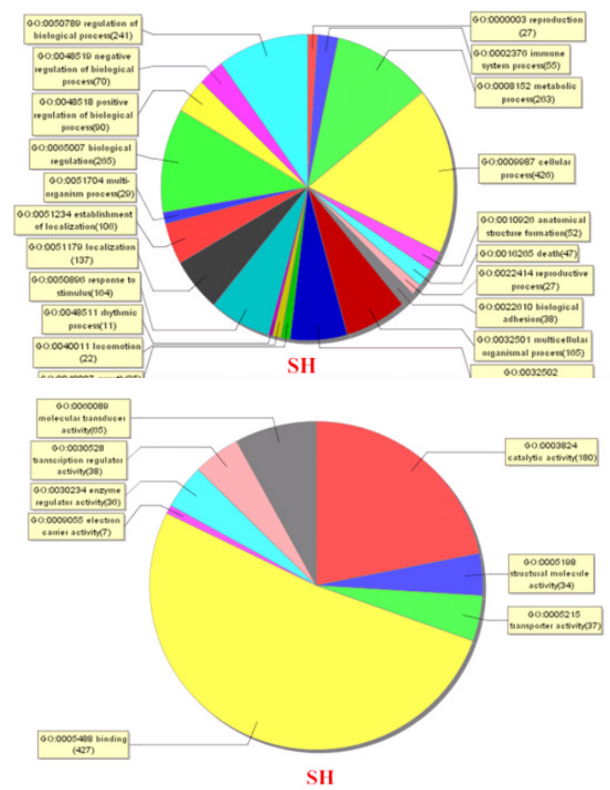

Figure 5. A. Results of GO analysis, which differentially expressed genes grouped in the cellular component categories; B. results of GO analysis, which differentially expressed genes grouped in the biological process categories; C. results of GO analysis, which differentially expressed genes grouped in the molecular function categories.

\section{Validation of microarray data}

To validate the microarray data, 13 genes were randomly selected for qRT-PCR. Housekeeping genes such as those encoding $\beta$-actin $(A C T B)$ and glyceraldehyde-3-phosphate dehydrogenase $(G A P D H)$, commonly used as internal controls for such analysis, were not suitable for normalization in these experiments, for their transcription was altered during myogenesis (Radonic et al., 2004; Pas et al., 2005). As in previous studies (Laborda, 1991; 
Fleming-Waddell et al., 2007; Vuocolo et al., 2007; White et al., 2008), RPLP0 was chosen as the ideal reference gene to normalize the data. The results for a panel of the 11 genes were in good agreement with the microarray data, indicating that our microarray data results reliably revealed the differences in gene expression profiles in skeletal muscle.

\section{DISCUSSION}

The sheep is an important domestic animal and model for many types of medically relevant research. An investigation of gene expression in ovine muscle would significantly advance our understanding of muscle growth. DNA microarray technology offers a novel approach to analyze transcriptome-wide expression profiling in cells or tissues under different stages or conditions. In this study the DEGs in sheep fetal skeletal muscle at different stages of gestation were analyzed, and the results that showed several genes were specifically expressed in PD and SH. PPP1R15A is a member of a group of genes whose transcript levels are increased following stressful growth arrest conditions and treatment with DNA-damaging agents. It plays a general role in negative growth control, including growth suppression and apoptosis in many cell types. MRPL1 may play a role in restricting the ability of bacteria to invade and grow in vivo (Rojo et al., 2007). However, its effects on muscle and adipose development is unknown. $R A R G$, a member of the nuclear hormone receptor family, is also known as NR1B3, and is known to interact with NCoR1 (Dowell et al., 1999). Loss of function of NCoR1 protein significantly increases the strength and power of mouse muscles (Yamamoto et al., 2011). $C A 4$, a member of the $C A$ family, belongs to the zinc metalloenzymes and has a role in inherited renal abnormalities of bicarbonate transport (Alvarez et al., 2007; Tian et al., 2010). C1QTNF1, a protein-coding gene, has a role in the regulation of glucose metabolic processes (Jeon et al., 2008; Chalupova et al., 2013). In our study, the PPP1R15A and MRPL1 genes were uniquely expressed in $\mathrm{SH}$, while the RARG, CA4 and C1QTNF1 genes were uniquely expressed in $\mathrm{PD}$ at the stage of 60 days, which suggests that these genes may play different roles in fetal growth and development in sheep. ITGBL1, a member of the EGFlike protein family, is associated with isolated growth hormone deficiency and abnormally short height. Too little growth hormone can cause short stature in children, and changes in muscle mass, cholesterol levels, and bone strength in adults (Eckman, 2010). CPXM2, a protein-coding gene, may be involved in cell-cell interactions. SIGLEC14 is a putative adhesion molecule. Sialic acid-binding receptor may activate associated receptors (Angata et al., 2006). $A P O B E C 3 G$ is a member of the cytidine deaminase gene family, a family of proteins that has been suggested to play an important role in innate anti-viral immunity (Takaori, 2005). In the present study, the ITGBL1,CPXM2, MRPL1 genes were only expressed in SH, and SIGLEC14 and $A P O B E C 3 G$ only expressed in PD at 90 days. This suggested that they may play different roles in the two breeds. HPSE is involved in embryo development, heparan sulfate turnover, hair growth and wound healing (Baker et al., 2012). RAB33B, a member of RAS oncogene family, plays important roles in defined steps of vesicular transport in protein secretion and the endocytosis pathway (Zheng et al., 1998). F2 plays a role in migration and proliferation of vascular smooth muscle cells, apoptosis and angiogenesis (Borissoff et al., 2010, 2011). $A D I P O Q$ is expressed in adipose tissue exclusively and modulates a number of metabolic processes, including glucose regulation and fatty acid oxidation (Diez and Iglesias, 2003). $A S G R 1$, encoding a subunit of the asialoglycoprotein receptor, plays a critical role in serum glycoprotein homeostasis (Benyair et al., 2011). FABP4 encodes the fatty acid-binding pro- 
tein found in adipocytes and delivers long-chain fatty acids and retinoic acid to their cognate receptors in the nucleus (Maeda et al., 2005). MGAT1 encodes a protein that is considered to be essential for normal embryogenesis (Jacobsson et al., 2012). HINT1 has been found to be a tumor-suppressing gene (Lee et al., 2004). HLA-DQB1 belongs to the HLA class II beta chain paralogs, and it plays a central role in the immune system and is also expressed in skeletal muscle tissue (Murray et al., 2007). In our research, HPSE, RAB33B, MRPL1, and PPP1R15A were only expressed in SH, and F2, ADIPOQ, ASGR1, FABP4, MGAT1, HINT1, and HLA$D Q B 1$ only expressed in PD at the stage of 120 days. For the three prenatal stages studied, the MRPL1 gene was especially expressed in $\mathrm{SH}$ in all stages. PPP1R15A was expressed in $\mathrm{SH}$ at 60 and 120 days. This suggested that these genes may be the genetic reasons for causing the skeletal muscle growth and development differences between PD and SH sheep in the embryonic stage. Additionally, the number of DEGs, i.e., 88, 128 and 340, was shown to be significantly differentially expressed between the two sheep breeds for the three stages. Also, the maximum number of DEGs was seen at 120 days, indicating that rapid myofiber proliferation included numerous genes during the myogenic process. With fetal growth and development, the number of DEGs increased, consistent with the rules of sheep skeletal muscle development. These results indicated that the difference in body weight between adult PD and SH sheep may depend on some DEGs at the embryonic stage.

\section{REFERENCES}

Alvarez BV, Vithana EN, Yang Z, Koh AH, et al. (2007). Identification and characterization of a novel mutation in the carbonic anhydrase IV gene that causes retinitis pigmentosa. Invest. Ophthalmol Vis. Sci. 48: 3459-3468.

Angata T, Hayakawa T, Yamanaka M, Varki A, et al. (2006). Discovery of Siglec-14, a novel sialic acid receptor undergoing concerted evolution with Siglec-5 in primates. FASEB J. 20: 1964-1973.

Ashmore CR, Robinson DW, Rattray P and Doerr L (1972). Biphasic development of muscle fibers in the fetal lamb. Exp. Neurol. 37: 241-255.

Baker AB, Gibson WJ, Kolachalama VB, Golomb M, et al. (2012). Heparanase regulates thrombosis in vascular injury and stent-induced flow disturbance. J. Am Coll. Cardiol. 59: 1551-1560.

Benyair R, Kondratyev M, Veselkin E, Tolchinsky S, et al. (2011). Constant serum levels of secreted asialoglycoprotein receptor sH2a and decrease with cirrhosis. World J. Gastroenterol. 17: 5305-5309.

Borissoff JI, Heeneman S, Kilinc E, Kassak P, et al. (2010). Early atherosclerosis exhibits an enhanced procoagulant state. Circulation 122: 821-830.

Borissoff JI, Spronk HM and Cate H (2011). The hemostatic system as a modulator of atherosclerosis. N. Engl. J. Med. 364: 1746-1760.

Chalupova L, Zakovska A and Adamcova K (2013). Development of a novel enzyme-linked immunosorbent assay (ELISA) for measurement of serum CTRP1: a pilot study: measurement of serum CTRP1 in healthy donors and patients with metabolic syndrome. Clin. Biochem. 46: 73-78.

Diez JJ and Iglesias P (2003). The role of the novel adipocyte-derived hormone adiponectin in human disease. Eur. J. Endocrinol. 148: 293-300.

Dowell P, Ishmael JE, Avram D, Peterson VJ, et al. (1999). Identification of nuclear receptor corepressor as a peroxisome proliferator-activated receptor alpha interacting protein. J. Biol. Chem. 274: 15901-15907.

Eckman AS (2010). Growth hormone test. MedlinePlus Medical Encyclopedia. Available at [http://www.nlm.nih.gov/ medlineplus/ency/article/003706.htm].

Fleming-Waddell JN, Wilson LM, Olbricht GR, Vuocolo T, et al. (2007). Analysis of gene expression during the onset of muscle hypertrophy in callipyge lambs. Anim. Genetics 38: 28-36.

Jacobsson JA, Rask-Andersen M, Riserus U, Moschonis G, et al. (2012). Genetic variants near the MGAT1 gene are associated with body weight, BMI and fatty acid metabolism among adults and children. Int. J. Obes. 36: 119-129.

Jeon JH, Kim KY, Kim JH, Baek A, et al. (2008). A novel adipokine CTRP1 stimulates aldosterone production. FASEB J. 22: 1502-1511.

Laborda J (1991). 36B4 cDNA used as an estradiol-independent mRNA control is the cDNA for human acidic ribosomal 
phosphoprotein PO. Nucleic Acids Res. 19: 3998.

Lee YN, Nechushtan H, Figov N and Razin E (2004). The function of lysyl-tRNA synthetase and Ap4A as signaling regulators of MITF activity in FcepsilonRI-activated mast cells. Immunity 20: 145-151.

Livak KJ and Schmittgen TD (2001). Analysis of relative gene expression data using real-time quantitative PCR and the 2(-Delta Delta C(T)) method. Methods 25: 402-408.

Maeda K, Cao H, Kono K, Gorgun CZ, et al. (2005). Adipocyte/macrophage fatty acid binding proteins control integrated metabolic responses in obesity and diabetes. Cell Metab. 1: 107-119.

Maier A, McEwan JC, Dodds KG, Fischman DA, et al. (1992). Myosin heavy chain composition of single fibres and their origins and distribution in developing fascicles of sheep tibialis cranialis muscles. J. Muscle Res. Cell Motility 13: 551-572.

McCoard SA, McNabb WC, Peterson SW, McCutcheon SN, et al. (2000). Muscle growth, cell number, type and morphometry in single and twin fetal lambs during mid to late gestation. Reprod Fertil Dev. 12: 319-327.

Murray JA, Moore SB, Van Dyke CT, Lahr BD, et al. (2007). HLA DQ gene dosage and risk and severity of celiac disease. Clin. Gastroenterol. Hepatol. 5: 1406-1412.

National Commission for Livestock and Poultry Genetic Resources (2011). National Genetic Resources of Livestock and poultry Sheep and Goat Breeds. China Agriculture Press, Beijing.

Pas MF, De Wit AA, Priem J, Cagnazzo M, et al. (2005). Transcriptome expression profiles in prenatal pigs in relation to myogenesis. J. Muscle Res. Cell Motil. 26: 157-165.

Rehfeldt C, Fiedler I, and Stickland NC (2004). Number and size of muscle fibres in relation to meat production. In: Muscle Development of Livestock Animals: Physiology, Genetics, and Meat Quality. Edited by te Pas MFW HH, Everts ME. Wallingford Oxfordshire: CAB Int, 1-37.

Radonic A, Thulke S, Mackay IM, Landt O, et al. (2004). Guideline to reference gene selection for quantitative real-time PCR. Biochem. Biophys. Res. Commun. 313: 856-862.

Rojo I, de Ilarduya OM, Estonba A and Pardo MA (2007). Innate immune gene expression in individual zebrafish after Listonella anguillarum inoculation. Fish Shellfish Immunol. 23: 1285-1293.

Russell RG and Oteruelo FT (1981). An ultrastructural study of the differentiation of skeletal muscle in the bovine fetus. Anatomy Embryol. 162: 403-417.

Takaori A (2005). Antiviral defense by APOBEC3 family proteins. Uirusu 55: 267-272.

Tian Y, Tang L, Cui J and Zhu X (2010). Screening for the carbonic anhydrase IV gene mutations in Chinese retinitis pigmentosa patients. Curr. Eye Res. 35: 440-444.

Vuocolo T, Byrne K, White J, McWilliam S, et al. (2007). Identification of a gene network contributing to hypertrophy in callipyge skeletal muscle. Physiol. Genomics 28: 253-272.

White JD, Vuocolo T, McDonagh M, Grounds MD, et al. (2008). Analysis of the callipyge phenotype through skeletal muscle development; association of Dlk1 with muscle precursor cells. Differentiation 76: 283-298.

Wilson SJ, McEwan JC, Sheard PW and Harris AJ (1992). Early stages of myogenesis in a large mammal: formation of successive generations of myotubes in sheep tibialis cranialis muscle. J. Muscle Res. Cell Motility 13: 534-550.

Yamamoto H, Williams EG, Mouchiroud L, Canto C, et al. (2011). NCoR1 is a conserved physiological modulator of muscle mass and oxidative function. Cell 147: 827-839.

Zheng JY, Koda T, Fujiwara T, Kishi M, et al. (1998). A novel Rab GTPase, Rab33B, is ubiquitously expressed and localized to the medial Golgi cisternae. J. Cell Sci. 111: 1061-1069. 